\title{
KEKUATAN DAN UMUR FATIK STRUKTUR PENOMPANG JAW CRUSHER DENGAN METODE ELEMEN HINGGA
}

\author{
Nurhayati $^{1}$, T. R Wijaya ${ }^{1}$ \\ ${ }^{1}$ Departemen Teknik Sipil Fakultas Teknik Institut Sains dan Teknologi Nasional \\ E-mail: deafella83@gmail.com
}

\begin{abstract}
ABSTRAK
Struktur yang bekerja dengan baik sesuai dengan kapasitasnya pembebanan statik yang berada dibawah batas luluh materialnya, dapat saja mengalami kegagalan saat beroperasi. Hal ini disebabkan karena struktur tersebut menerima tambahan beban dinamis yang terjadi berulang dalam waktu yang cukup lama yang lebih dikenal dengan beban siklik atau beban fatik. Tujuan dari analisa fatik ini untuk mengetahui berapa umur pakai struktur sehingga dapat direncanakan perbaikan dan perkuatan struktur tanpa harus mengganggu proses operasi. Dalam pengoperasiannya struktur penompang jaw crusher menerima beban fatik dari equipment yang berdiri diatasnya. Analisa fatik struktur dilakukan dengan menggunakan metode elemen hingga dengan tujuan untuk mendapatkan hasil analisa yang lebih akurat. Analisa yang digunakan adalah analisa untuk tipe contant amplitude events. Berdasarkan hasil analisa didapat umur struktur penompang jaw crusher adalah selama 67000 siklus atau 8 bulan 28 hari.
\end{abstract}

Kata Kunci: fatik, metode elemen hingga, jaw crusher, constant amplitude events

\begin{abstract}
The structure would be work well accordance to its capacity and it has the static loadings that were under limit the yield strength of the material, can be subjected to failure during operations, and this is because the structure receives additional dynamic loads that occur repeatedly within a long period of time as known as cyclic loads or fatigue loads. The purpose of the fatigue analysis is to find out the working life of structure so, the structure can be planned to repair and strengthen without disturbing the operation process. In real operations, the structure support of jaw crusher receives fatigue load from the equipment which standing on it. Structure alaysed by used finite element method with the aim to get more accurate analysis results. The type of analysis used is constants amplitude events. Based on the analysis results obtained the life of the jaw crusher is for 67000 cycles or 8 months 28.
\end{abstract}

Keywords: fatigue, finite element, jaw crusher, constant amplitude events 


\section{PENDAHULUAN}

Fatik merupakan salah satu modus kegagalan yang diakibatkan oleh beban yang bekerja secara berulang (Fuchs, Ralph, 1983). Kegagalan material ini ditandai dengan kerusakan yang terjadi secara tiba-tiba pada tingkat tegangan dibawah tegangan leleh (yield strength). Ada tiga tahapan terjadinya kerusakan fatik, yaitu: inisiasi retak / awal timbulnya retak (crack initiation), perambatan retak (crack propagation) dan akhirnya patah atau gagal (fracture) (Adam, 2011). Lokasi awal retak akibat fatik biasanya ada pada daerah yang mememiliki cacat permukaan, sedangkan percepatan rambatan retak sangat berpengaruh pada kekuatan material dan jenis serta besarnya beban yang bekerja (Hasan, 2007). Selama bertahun-tahun, banyak kegagalan tak terduga pada peralatan dan berbagai mesin telah terjadi di seluruh dunia industri dan kegagalan yang dominan terjadi diakibatkan oleh kegagalan fatik (Karaagac, 2002).

\section{Tujuan Penelitian}

Dalam penelitian ini, kegagalan (fraktur) dari struktur pennompang jaw crusher dengan beban dinamik sebagai topik investigasi. Namun, penelitian ini dimaksudkan untuk memperkenalkan mekanika fraktur dari sudut pandang aplikasi struktur sipil dengan fokus pada analisis tegangan dan fatik dengan menggunakan metode elemen hingga.

\section{METODOLOGI PENELITIAN}

Metode penelitian yang dilakukan berupa analisa secara aplikasi dan diverifikasi dengan batas nilai yang telah ditetapkan dalam ASME VIII.

\section{Objek Penelitian}

Objek penelitian merupakan rangka struktur baja penompang Jaw Crusher yang menerima gaya atau beban fatik dari equipment yang ditopangnya, seperti terlihat pada Gambar 1 berikut ini.

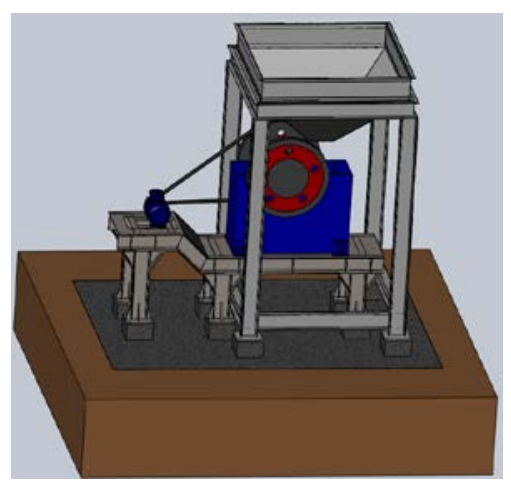

Gambar 1. Struktur Penompang

\section{Penetuan Batas Umur Struktur dengan S-N Curve}

Pada tahapan ini, penulis menggunakan ASME VIII, Division 2 sebagai referensi. Alasan penulis memilih ini, karena ASME disusun berdasarkan sifat material dan juga suhu kerja. Penulis berpendapat kondisi ini sesuai dengan kondisi benda uji.
Berdasarkan ASME II part D, didapatkan material properties sebagai berikut:

- Allowable Stress Maksimum: 114MPa

- Tensile strength: 400MPa

- $\quad$ Nilai batas bawah tegangan : $171 \mathrm{MPa}$

- Nilai batas atas tegangan : $171 \mathrm{MPa}$

Dengan nilai material properties seperti diatas, didapatkan koefisien kurva fatik yang mengacu pada ASME VIII seperti pada Tabel di bawah ini:

Tabel 1. Koefisien Kurva Fatik

\begin{tabular}{|c|c|c|}
\hline $\mathbf{C}$ & $\mathbf{0 4} \leq \mathbf{S} \leq \mathbf{1 0 4}$ & $\mathbf{1 0 5} \leq \mathbf{S} \mathbf{3} \mathbf{4 8 8 1}$ \\
\hline 1 & $1.89 \mathrm{E}+01$ & $2.11 \mathrm{E}+01$ \\
2 & $1.48 \mathrm{E}-01$ & $1.54 \mathrm{E}-01$ \\
3 & $-2.44 \mathrm{E}+00$ & $4.49 \mathrm{E}-01$ \\
4 & $-6.37 \mathrm{E}-02$ & $3.65 \mathrm{E}-04$ \\
5 & $-6.91 \mathrm{E}-02$ & $-8.98 \mathrm{E}-05$ \\
6 & $5.38 \mathrm{E}-03$ & $0.00 \mathrm{E}+00$ \\
7 & $1.96 \mathrm{E}-02$ & $0.00 \mathrm{E}+00$ \\
8 & $-1.39 \mathrm{E}-04$ & $0.00 \mathrm{E}+00$ \\
9 & $-6.51 \mathrm{E}-04$ & $0.00 \mathrm{E}+00$ \\
10 & $0.00 \mathrm{E}+00$ & $0.00 \mathrm{E}+00$ \\
11 & $0.00 \mathrm{E}+00$ & $0.00 \mathrm{E}+00$ \\
\hline
\end{tabular}

(Sumber: ASME VIII, Table 3.F)

$$
\begin{aligned}
& \text { Catatan: } \\
& \mathrm{E}_{\mathrm{Fc}}=195 \mathrm{Gpa}(\mathrm{ASME} \mathrm{VIII}) \\
& \mathrm{C}_{\mathrm{us}}=6.89 \mathrm{E}+00
\end{aligned}
$$

\section{Metode Elemen Hingga}

Metode elemen hingga dilakukan dengan bantuan software Solidwork versi 2016, dengan langkah-langkah berikut:

Mempersiapkan model struktur, dengan melakukan pemeriksaan terhadap bagian-bagian dari model yang tumpang tindih (interferences) dan perakitan yang tidak terdefinisi dengan baik (assembly), dilakukan modifikasi seperlunya untuk mendapatkan model yang bebas tumpang tindih dan terdefinisi dengan baik (no fullydefined assembly).

Memasukkan data material yaitu JIS G 3101 SS400 dan JIS G 4051 S45C yang merupakan baja karbon rendah untuk aplikasi struktur umum struktur baja. Properti yang digunakan adalahproperti mekanik dan tabel tegangan (S-N Curve) seperti yang tertera pada ASME II part D. Mendefinisikan jenis sambungan pada model struktur yang berupa kontak, join, dan system koneksi antar member (contact, joint, connection).

Mendefinisikan metode dan membuat meshing, serta menghidari meshing satu elemen dengan dua arah berbeda yang dapat menyebabkan ketidakakuratan hasil nantinya. 


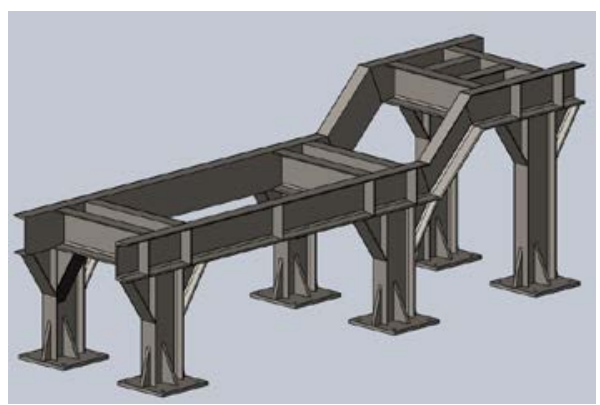

Gambar 2. Model Struktur Penompang Jaw Crusher

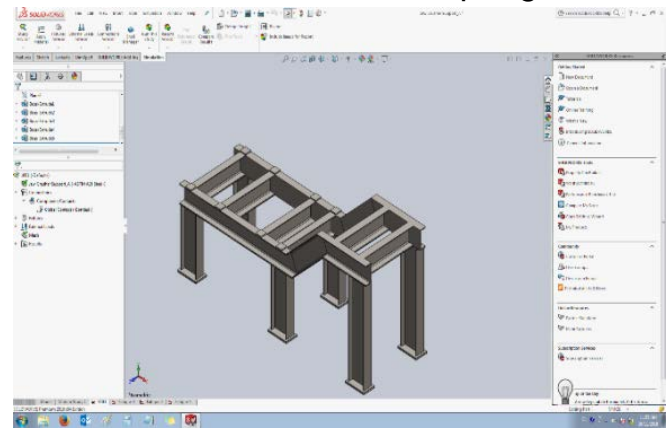

Gambar 3. Pendefinisian Jenis Sambungan

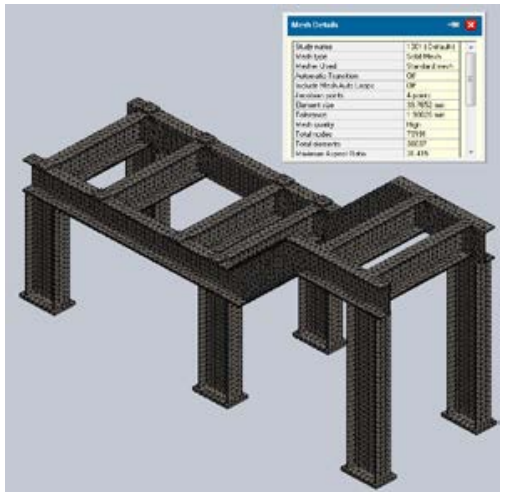

Gambar 4. Hasil Meshing Struktur Pendukung Jaw Crusher

Memasukkan kondisi batas dan pembebanan pada struktur yang berupa tumpuan fixed, beban akibat equipment naik yang bersifat static maupun dinamik.

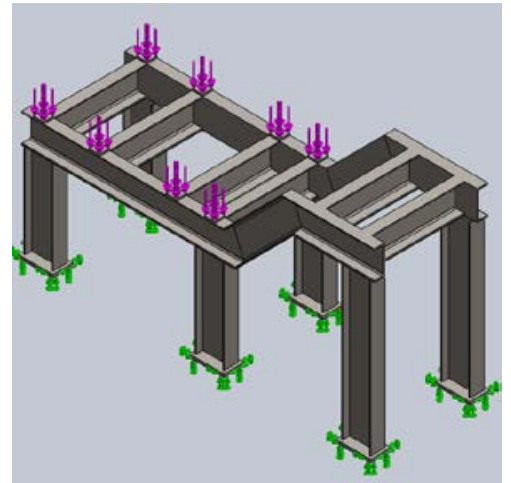

Gambar 5. Kondisi Batas Struktur

Memasukkan solusi structural statis dan analisa fatik, parameter masukan (input)

Menjalankan proses simulasi dan perhitungan.
Memeriksa validitas hasil perhitungan dengan matriks kualitas elemen dan tes konvergensi. Apabila matriks kualitas elemen semakin bergerak ke nilai satu, maka bentuk meshing yang dihasilkan semakin proporsional dan seragam dengan demikian hasil solusi perhitungan dinyatakan valid.

Bila hasil perhitungan tidak valid maka kembali pada langkah persiapan model untuk dilakukan perbaikanperbaikan. Apabila validitas hasil perhitungan tercapai maka dilanjutkan pada analisa hasil dan penarikan kesimpulan.

\section{Analisa Umur Fatik}

Sebelum analisa umur fatik dilakukan, diperlukan pengambilan keputusan terhadap parameter masukan (input) yang mencakup:

\section{Jenis Analisa Fatik}

Terdiri atas analisa umur regangan (strain-life), analisa umur tegangan (stress-life) dan analisa umur retak (crack-life).

Analisa strain-life digunakan untuk siklus rendah (Low Cycle Fatigue/LCF) dibawah 100,000 siklus, sedangkan analisa stress-life digunakan untuk siklus tinggi (High Cycle Fatigue/HCF) diatas 100,000 siklus, dan analisa crack-life atau fracture mechanics dimulai pada cacat yang diketahui ukurannya lalu menentukan pertumbuhan retak, namun jenis analisa ini tidak didukung oleh perangkat lunak SOLIDWORK. Sesuai dengan desain umur tak-hingga (infinite-life design), maka dipilih jenis analisa stress-life.

\section{Faktor Modifikasi Fatik}

Faktor modifikasi fatik terdiri dari:

Faktor kekuatan fatik (fatigue strength factor / Kf), yaitu pengali yang digunakan untuk mengurangi kekuatan fatik yang diberikan oleh S-N Curve sebagai bentuk kompensasi terhadap adanya perbedaan antara kekuatan fatik material dalam pembebanan sesungguhnya dengan pembebanan dalam pengujian fatik material. Pada penelitian ini, diambil faktor kekuatan fatik sebesar 1 atau diasumsikan tidak ada perbedaan kekuatan fatik antara pembebanan pada model dengan pembebanan saat pengujian material untuk menghasilkan S-N Curve.

Faktor skala pembebanan (loading scale factor), merupakan nilai yang akan mengali atau membagi semua tegangan dinamis baik tegangan alternating maupun rata-rata. Hal ini berguna untuk menghindari perhitungan ulang statik struktural bila kondisi pembebanannya diubah untuk keperluan analisa dengan variasi pembebanan. Pada penelitian ini, diambil faktor skala pembebanan sebesar 1 atau tidak ada variasi pembebanan yang diberikan.

\section{Komponen Tegangan}

Komponen tegangan (stress component), merupakan tegangan referensi yang akan digunakan dalam perhitungan untuk mencari pola tegangan dinamis (tegangan maksimum $/ \sigma_{\max }$, tegangan alternating $/ \sigma_{a}$, 
tegangan rata-rata $/ \sigma_{m}$, dan tegangan minimum $/ \sigma_{\min }$ ). Opsi pada komponen tegangan adalah sebagai berikut: komponen $\mathrm{X}$, komponen $\mathrm{Y}$, komponen $\mathrm{Z}$, komponen $\mathrm{XY}$, komponen $\mathrm{YZ}$, komponen $\mathrm{XZ}$, tegangan Von Mises, tegangan Signed Von Mises, tegangan geser maksimum, tegangan principal maksimum, dan tegangan absolut principal maksimum. Pada penelitian ini, diputuskan untuk menggunakan tegangan von-Mises $\left(\sigma_{v m}\right)$ yang dihasilkan dari perhitungan statik struktural sebagai komponen tegangan referensi.

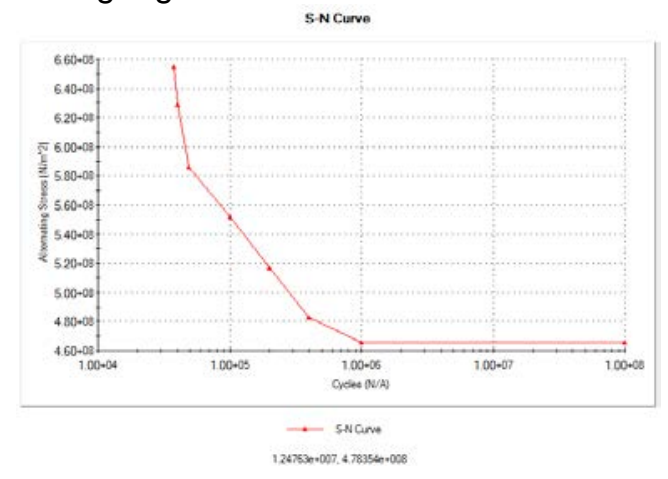

Gambar 6. S-N curve SS 400

\section{Satuan Umur}

Satuan umur (life units), merupakan satuan yang digunakan pada siklus, terdiri dari siklus, blok, detik, menit, dan jam. Dan pendefinisian siklus yang menyatakan berapa banyak siklus dalam satu satuan. Pada penelitian ini, diambil detik sebagai satuan umur, dan satu siklus sama dengan satu detik, sehingga didapatkan frekuensi pembebanan dinamis sebesar 1 Hertz.

\section{Jenis Interpolasi}

Jenis interpolasi (interpolation type), terdiri dari log-log, semi-log, dan linear. Karena tidak semua titik tegangan alternating tersedia dalam S-N Curve, maka apabila hasil perhitungan tegangan alternating jatuh pada titik yang tidak tersedia, maka diperlukan proses interpolasi dari titik-titik yang diketahui dalam S-N Curve untuk mendapatkan nilai yang sesuai. Pada penelitian ini, digunakan jenis interpolasi semi-log, dimana linier pada sumbu $Y$ (tegangan alternating), dan logaritmik berbasis 10 pada sumbu $x$ (umur fatik).

\section{Jenis Pembebanan Dinamis}

Berdasarkan pada amplitudonya, beban dibagi menjadi amplitudo konstan dan non konstan, sedangkan berdasarkan pada pola pembebanannya, beban dibagi menjadi beban proporsional dan non proporsional. Pembebanan proporsional dengan amplitudo konstan, seperti halnya pada tes fatik untuk menghasilkan S-N Curve, sumbu tegangan prinsipalnya tidak berubah terhadap waktu sehingga lokasi fatik kritis dapat lebih mudah diindikasikan.

Pada penelitian ini, diasumsikan jenis pembebanan dinamis dengan amplitudo konstan sebesar $5 \%$ dari tegangan rata-ratanya $\left(\sigma_{m}\right)$, pertimbangan ini diambil karena melihat kondisi pembebanan pada struktur yang relatif lebih stabil. Kondisi pembebanan yang dipilih adalah pembebanan proporsional mengikuti kondisi masing-masing bagian struktur yang dihasilkan dari perhitungan statik strukturalnya.

Efek Tegangan Rata-Rata

Pada kurva S-N, jenis pembebanan yang digunakan adalah fully-resersed dengan amplitude konstan maka, penulis menggunakan jenis pembebanan yang sama pada metode ini.

\section{HASIL ANALISIS}

\section{Damage}

Kegagalan struktur dengan menggunakan metode analisis elemen hingga sudah mencapai 100\% untuk seluruh struktur saat sudah mencapai $10^{6}$ siklus, yang dapat dilihat pada Gambar 7.

Metode S-N curves tidak memberikan informasi mengenai besarnya kegagalan fatik pada struktur. S-N curves memberikan batasan tegangan yang diijinkan terjadi pada struktur untuk mencapai umur fatik yang diinginkan. Pada penelitian ini S-N curves memberikan batasan maksimum tegangan yakni $103 \mathrm{MPa}$, untuk mencapai struktur penompang jaw crusher memiliki umur fatik tak hingga (melebihi 10 tahun).

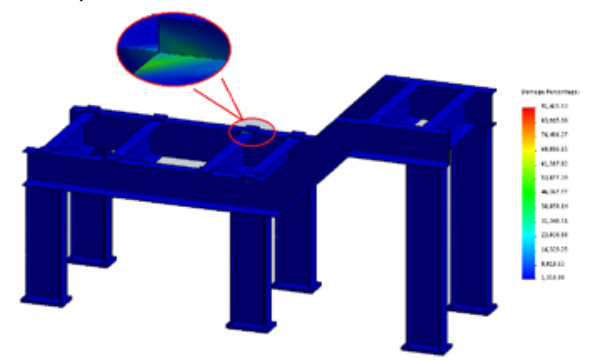

Gambar 7. Damage Percentage

2. Life

Umur konstruksi struktur penompang jaw crusher dalam beberapa variasi kejadian dengan menggunakan program berbasis elemen hingga Solidworks maksimum adalah 223.000 siklus (2 tahun, 5 bulan 12 hari) untuk balok penyangga, sedangkan untuk member struktur yang lain ratarata $10^{6}$ siklus (10 tahun). Umur terpendek terdapat pada plate penumpu denngan jumlah siklus 67.000 siklus atau setara dengan 8 bulan 28 hari atau dapat pula dilihat pada Gambar 8.

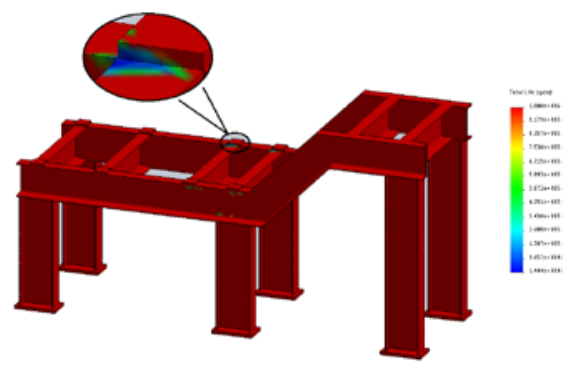

Gambar 8. Total Cycles

Sedangkan dengan menggunakan metode analisis S-N curve untuk umur fatik tidak terbatas (infinite life), batas tegangan yang aman adalah $103 \mathrm{MPa}$ Pada perencanaan umur fatik terbatas (finite life), yang kegagalan komponen dapat diprediksi dan dikontrol (damage tolerant) maka perencana harus menggunakan tingkat tegangan 
sedikit diatas tegangan operasi sebenarnya, kemudian ketika jumlah siklus pembebanan sudah mendekati batas umur yang ditentukan maka komponen harus dievaluasi untuk mengantisipasi kerusakan yang bakal terjadi.

Perhitungan estimasi fatik secara langsung dengan cara di atas dapat dilakukan dengan syarat asumsi komponen tidak ada cacat retak dan homogen. Pada komponen yang memiliki asumsi ada cacat retak maka perlu diperhitungkan dengan menggunakan pendekatan yang lebih akurat yaitu pendekatan mekanika retakan.

3. Letak Kondisi Ter-kritis

Dengan metode elemen hingga diketahui kondisi terkritis pada struktur penompang jaw crusher ada di top flange beam support yaitu NODE 36, karena memiliki umur terpendek dengan 67000 siklus, terlihat pada Gambar 9.

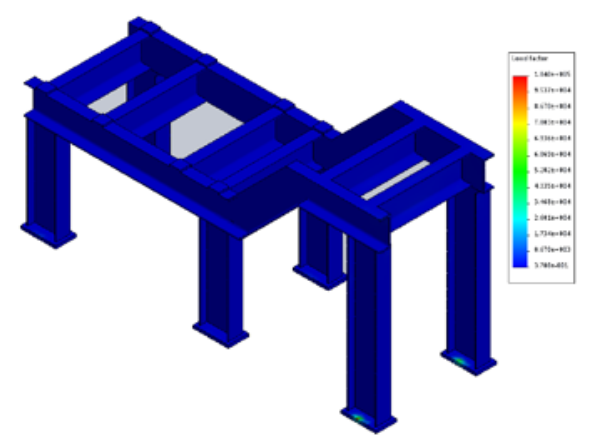

Gambar 9. Load Factor

Sedangkan untuk analisis dengan metode S-N curves tidak memberikan informasi mengenai daerah atau lokasi pada struktur yang mengalami kegagalan terlebih dahulu (ter-kritis). Hal ini dikarenakan S-N curves tidak menganalisa distribusi tegangan, hanya menganalisa tegangan berdasarkan sifat material.

\section{KESIMPULAN}

Metoda pendekatan tegangan atau kurva S-N dapat digunakan dalam perencanaan untuk mengestimasi umur fatik komponen secara langsung dengan syarat mengacu pada asumsi bahwa komponen tersebut adalah material logam, memiliki komposisi yang homogen, tidak memiliki cacat dan retak.

Pada perencanaan umur fatik terbatas (finite life), pada metode S-N curve dengan pembatasan tegangan sama dengan metode elemen hingga (224.08 MPa) didapatkan jumlah siklus 150.399. Sedangkan dengan metode elemen hingga didapatkan nilai 67.000 siklus.

Hal ini dimungkinkan terjadi karena:

1. Perbedaan Distribusi Tegangan

2. Pengaruh Tegangan amplitude

3. Frekwensi Pembebanan

\section{REFERENSI}

Adam, K. (2011). Faktor Perpatahan dan Kelelahan pada Kekuatan Bahan Material, ILTEK, Volume 6, Nomor 12.

Akuan, A. (2007). Kelelahan Logam. Jurusan Teknik Metalurgi Fakultas Teknik, Universitas Jenderal Achmad Yani.

Anderse, MR. (1998). Fatigue Crack Initiation and Growth in Ship Structure, Thesis Department of Naval Architecht of Offshore Engineering. Denmark: Technical university of Denmark.

Bahreini, R. S., Nematollahi, A. F. \& Jafari, A. (2016). Experimental and Finite Element Study of Bending Fatigue Failure: A Case Study on Main Shaft of a Gyrator Crusher. International Journal of Civil and Environmental Engineering, 10(11), 1387 - 1392.

Bolotin, V.V. (1999). Mechanics of fatigue. Boca Raton, CRC Press.

Fuchs, H.O., \& Ralph, I. (1983). Metal Fatigue in Engineering, John Willey \& Sons. New York.

Iridiatadi, H, Ir, MSIE, Ph.D. (2014). Penerapan Fatigue Managemen di Industri, RSK \& E ITB.

Krupp, U. (2007). Fatigue Crack Propagation in Metals and Alloys.

Lloyd, G. (2008). Rules for classification and construction ship technology of Chemical Tanker.

McDowell, D.L., \& Dunne, F.P.E. (2010). International Journal of Fatigue, 1521-1542. Cited in https://www.journals.elsevier.com/internationaljournal-of-fatique. [16 Februari 2019]

Nur, H, (2007). Laju Perambatan Retak Plat Aluminium 2024 T3 Dengan Pola Lubang Pada Beban Fatik Uniaksial Amplitudo Konstan, Jurusan Teknik Mesin Fakultas Teknologi Industri Institut Teknologi Sepuluh November Surabaya.

Rusiński, E., Moczko, P., Odyjas, P. \& Pietrusiak, D. (2013). Investigations of Structural Vibrations Problems of High-Performance Machines. Faculty of Mechanical Engineering, Belgrade, 41, 305 - 310.

Rusiński, E., Moczko, P., Pietrusiak, D. \& Przybyłek, G. (2013). Experimental and Numerical Studies of Jaw Crusher Supporting Structure Fatigue Failure. Journal of Mechanical Engineering, 59(9), 555 563. Cited in https://www.researchgate.net/journal/00392480 Strojniski Vestnik. [16 Januari 2019]

Swierstra, E.P. (2017). Fatigue Assessment in Finite Element Analysis. MSc Thesis. Department of Structural Engineering, Faculty of Civil Engineering and Geosciences, Delft University of Technology, Delft, The Netherlands.

Suresh, S. (1998). Fatigue of Materials, 2nd ed. Cambridge University Press.

Taufik, A. (2003). Paper: Aplikasi Failure Analysis Diagram untuk Mengevaluasi Integritas Mekanik Pipa Transmisi Gas yang mengandung Cacat pada Lasan, Indonesian Pipeline Technology. ITB. Bandung. 
Halaman ini sengaja dikosongkan 